\title{
Plasmodium falciparum infection during pregnancy in an unstable transmission area in eastern Sudan
}

G. Elghazali', I. Adam², A. Hamad ${ }^{3}$ and M.I. El-Bashir ${ }^{2}$

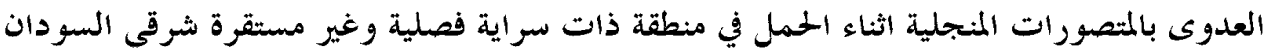

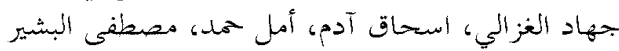

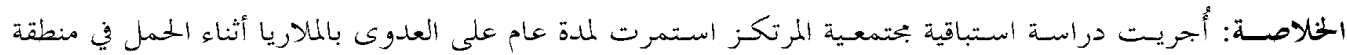

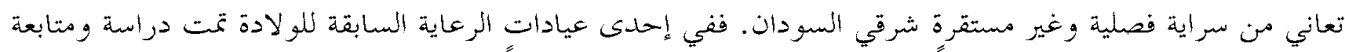

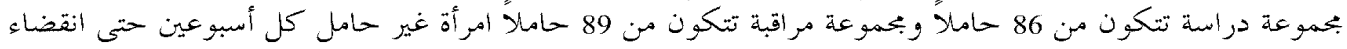

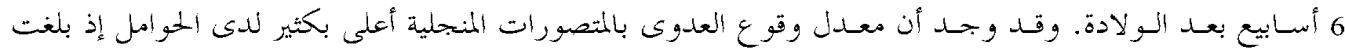

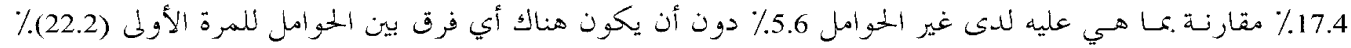

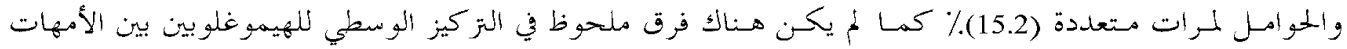

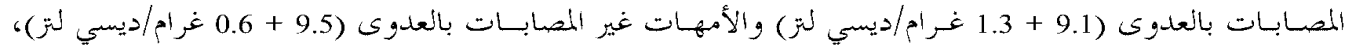

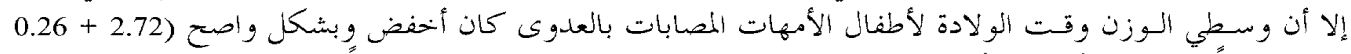

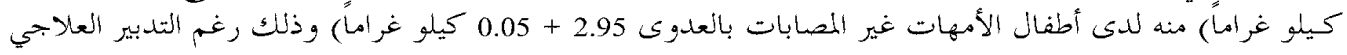

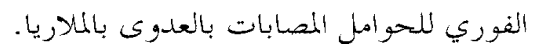

ABSTRACT A 1-year prospective community-based study of malaria during pregnancy was conducted in an area of seasonal and unstable malaria transmission in eastern Sudan. At a village antenatal clinic, 89 nonpregnant controls and 86 pregnant women were enrolled and followed every 2 weeks until 6 weeks after delivery. The incidence of Plasmodium falciparum infection was significantly higher among pregnant than control women (17.4\% versus $5.6 \%$ ) with no difference between primigravidae and multigravidae $(22.2 \%$ versus $15.2 \%$ ). There was no significant difference in the mean haemoglobin concentration between infected and uninfected mothers $(9.1 \pm 1.3$ versus $9.5 \pm 0.6 \mathrm{~g} / \mathrm{dL})$ but the mean birth weight of their babies was significantly lower $(2.72 \pm 0.26$ versus $2.95 \pm 0.05 \mathrm{~kg})$ despite prompt case management of infected women.

Infection à Plasmodium falciparum pendant la grossesse dans une zone de transmission saisonnière et instable au Soudan oriental

RESUME Une étude communautaire prospective d'un an sur le paludisme pendant la grossesse a été réalisée dans une zone de transmission du paludisme saisonnière et instable au Soudan oriental. Dans une consultation prénatale d'un village, 86 femmes enceintes et 89 femmes non enceintes (témoins) ont été recrutées pour l'étude et suivies toutes les 2 semaines jusqu'à 6 semaines après l'accouchement. L'incidence de l'infection à Plasmodium falciparum était significativement plus élevée chez les femmes enceintes que chez les femmes témoins (17,4\% contre 5,6\%) sans différence entre les primigestes et les multigestes (22,2\% contre $15,2 \%)$. II n'existait aucune différence significative dans la concentration moyenne d'hémoglobine entre les mères infectées et celles non infectées $(9,1 \pm 1,3$ contre $9,5 \pm 0,6 \mathrm{~g} / \mathrm{dL})$ mais le poids de naissance moyen de leurs bébés était significativement plus bas $(2,72 \pm 0,26$ contre $2,95 \pm 0,05 \mathrm{~kg}$ ) malgré une prise en charge rapide des femmes enceintes infectées.

${ }^{1}$ Department of Microbiology and Immunology; ${ }^{2}$ Malaria Research Centre, Department of Biochemistry, Faculty of Medicine, University of Khartoum, Khartoum, Sudan.

${ }^{3}$ National Laboratory, Ministry of Health, Khartoum, Sudan.

المجلة الصحية لشرق المتوسط، منظمة الصحة العالمية، المجلد التاسع، العدد ع، ب... 


\section{Introduction}

In Africa each year around 24 million women become pregnant in malaria-endemic areas. Pregnancy increases susceptibility to malaria and pregnant women are more likely to develop clinical attacks of malaria and serious complications than non-pregnant women of the same age. The increased susceptibility of pregnant women to malaria is thought to be, in part, the result of a certain degree of immune suppression during pregnancy required for retention of the fetal allograft $[1,2]$.

The increased risk of malaria in pregnant women is associated with serious adverse effects in pregnancy, leading to abortion, preterm labour [3], intrauterine growth retardation [4], intrauterine fetal death and low birth weight [5]. In addition to the effect of malaria on the fetus, malaria causes maternal anaemia, which contributes significantly to maternal morbidity and may be a risk factor for maternal death by increasing the case fatality rate in postpartum haemorrhage [6]. Malaria infection in the mother is also a risk factor for perinatal mortality and morbidity by reducing the baby's birth weight [7].

There are some distinctive features of the epidemiology of malaria during pregnancy that are important in terms of raising relevant research questions about the basic immunological processes, as well as in deciding the control strategies to be applied. First, the susceptibility to malaria infection and severity of clinical manifestations of malaria are determined by the level of prepregnancy immunity, which largely depends on the intensity and stability of malaria transmission [8]. Secondly, an important epidemiological aspect is the effect of parity of the pregnant woman on susceptibility to and severity of malaria infection.
In areas that are highly endemic for Plasmodium falciparum infection, adult women have acquired substantial protective immunity to malaria through repeated prior infections [8]. Although the prevalence and density of $P$. falciparum parasites are higher in pregnant women than in nonpregnant women, most infections remain asymptomatic [9-11], with little clinical consequences at least among multigravidae. The only clearly established beneficial effects of malaria chemoprophylaxis during pregnancy are to reduce maternal anaemia and increase the baby's birth weight in primigravidae (first pregnancy) [12]. Primigravidae in particular are an exception and suffer deleterious effects of malaria (particularly during the second trimester) whereas complications are less frequent in women who have had multiple pregnancies (multigravidae), indicating that the protective immunity in pregnancy is a function of parity [13]. The reason for this is unclear; immune suppression is probably more marked in primigravidae but it is also possible that protective immunity may be acquired in the reproductive tract through malaria infection during the first pregnancy, reducing susceptibility in later pregnancies [10].

In areas where malaria transmission is seasonal and unstable, both the mother and her fetus can suffer the most severe consequences of the infection [11]. In these areas, it is believed the degree of acquired immunity of the women prior to pregnancy is likely to be low or poorly developed and the epidemiological profile and clinical pattern of disease are different from that seen in highly endemic areas [14]. While the epidemiology of malaria during pregnancy has been extensively studied in highly endemic areas, very little data are available from areas with seasonal and unstable ma-

المجلة الصحية لشرق المتوسط، منظمة الصحة العالمية، المجلد التاسع، العلد ع، بr. 
laria [15]. The present study was conducted to investigate the pattern of malaria morbidity during pregnancy among women living in one area of eastern Sudan.

\section{Methods}

\section{Study area}

The study was performed in Elhara Eloul, a village in the New Halfa area in the eastern Sudan. The population in the last census in 2001 was 1841. The New Halfa town was constructed in 1964 to settle the inhabitants of old Halfa in the northern border of Sudan who were displaced after construction of the High Dam on the Nile in Egypt. The area itself is made up of iso-villages constituting 400000 inhabitants. It is an agricultural area, $500 \mathrm{~km}$ from Khartoum and $450 \mathrm{~m}$ above sea level, located around $15^{\circ}$ $\mathrm{N} 35^{\circ} \mathrm{E}$. The average annual rainfall is 238 $\mathrm{mm}$ and the average annual relative humidity is $35 \%$. Cotton, sorghum, groundnut, sugar cane and various vegetables are cultivated in about $1700 \mathrm{~km}^{2}$ of the area. There is a permanent irrigation system. The area is mesoendemic for falciparum malaria, with peak transmission following the rainy season (September to January). The predominant malaria parasite species is $P$. falciparum, with $P$. vivax and $P$. malariae occasionally seen. Anopheles arabiensis is the sole malaria vector in the area. The incidence of malaria varies considerably from year to year depending on the rainfall [16]. There is 1 teaching hospital, 25 dispensaries and 1 single-doctor hospital. Bed nets and malaria chemoprophylaxis are not used in the area.

\section{Study design and population}

This was a prospective community-based study that was timed to begin before the malaria transmission season (late June) and continue for 1 year. An antenatal clinic su- pervised by an obstetrician was initiated in the health centre in the village. Our aim was to enrol and follow-up all pregnant women in the village, an average of $6-10$ women per day. All pregnant women were encouraged to attend the antenatal clinic. Free medical care (including free medication) was provided, so it was unlikely that the women sought medical advice elsewhere. For each pregnant woman the nearest nonpregnant woman neighbour, matched for age and socioeconomic status, was asked to participate in the study as part of a control group.

\section{Data collection}

The clinical and obstetric history of the women was recorded in detail, including last menstrual period, gravidity, parity and history of abortion or preterm labour. At the time of enrolment, pregnant women and their controls were classified as low- or high-risk according to their obstetric history (any history of repeated abortion, preterm labour or pre-eclamptic toxaemia).

Obstetric and physical examinations were carried out on pregnant women (blood pressure, pallor, and fundal level). The pregnancy and its duration were calculated from the last menstrual period and confirmed by ultrasound. Control women were given a general physical examination and ultrasound was performed to exclude pregnancy. After enrolment, pregnant women were requested to present to the antenatal clinic once every 2 weeks until 6 weeks after delivery. Control women also attended every 2 weeks. Our team (medical officer and a microscope technician) was available daily to take care of those presenting with complaints. Initially and at every visit women were asked specifically about symptoms suggestive of malaria (fever, headache, sweating, joint pain and vomiting). Parasitological and detailed medical

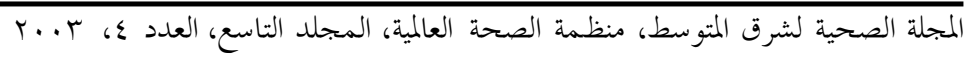


examinations were carried out in cases presenting to the medical staff complaining of fever or giving a recent history of fever (within the past 3 days). Due to the high rate of chloroquine resistance in the area [17], confirmed falciparum infections were treated with quinine $10 \mathrm{mg} / \mathrm{kg}$ body weight 3 times/day for 7 days.

At every visit, pregnant women were supplied with ferrous sulfate $(200 \mathrm{mg} / 1$ tablet per day) and folic acid ( $0.5 \mathrm{mg} / 1 \mathrm{tab}-$ let per day). Deliveries were conducted by trained midwifes and the birth weight was recorded (to the near $50 \mathrm{~g}$ ) within 24 hours of delivery. High-risk patients were advised to deliver in New Halfa hospital under the supervision of an obstetrician.

\section{Parasitology and clinical tests}

Blood was taken by finger prick from subjects complaining of fever and thick and thin blood films were prepared and stained with Giemsa ( $\mathrm{pH} 7.0$, diluted with phosphate buffered saline). The thick blood films were used to detect the malaria parasite and the thin films for defining the parasite species. For parasite detection, 100 fields were examined irrespective of the parasites encountered. The parasitological data were crosschecked by another technician, blind to the results and verified by the supervisor if there was any controversy. The number of asexual parasites per 200 leukocytes was counted and parasite densities (asexual parasites/ $\mu \mathrm{L}$ ) were calculated assuming a normal value of 6000 leukocytes $/ \mu \mathrm{L}$ blood. The haemoglobin concentration was measured using a modified Sahli method [18].

A malaria episode was defined by a positive parasitology result, regardless of symptoms. An episode of symptomatic malaria was fever (oral temperature > $37.5^{\circ} \mathrm{C}$ ) or a history of fever together with parasitaemia. Anaemia was defined as a haemoglobin concentration $<8 \mathrm{~g} / \mathrm{dL}$ and severe anaemia as $<5 \mathrm{~g} / \mathrm{dL}$. Abortion was defined as expulsion of a dead fetus before 28 weeks gestation. Premature labour was labour before completion of 37 weeks of gestation. Perinatal death was death from 28 weeks in utero until the age of 1 week. Low birth weight was defined as birth weight less than $2500 \mathrm{~kg}$.

\section{Statistical analysis}

Data were entered into a computer database and were analysed using the statistical program SPSS for Windows, version 11.5. Student's $t$-test, chi-squared and Fisher exact test were used as appropriate. $P<0.05$ was regarded as significant.

\section{Ethical considerations}

Women consented to participate in the study after being given adequate information on the objectives and benefits of the project. The study was monitored and supervised by qualified medical personnel whose first responsibility was the welfare of the patients enrolled in the study. At all times, proper patient management took priority over continuation of the study. The study was carried out following WHO Guidelines for good clinical practice [19]. To maintain the privacy of women participating in the study, patient data were treated as confidential and each woman was coded in the computer database.

\section{Results}

Out of 209 women enrolled, 175 were studied (86 pregnant and 89 control women) during 2 dry seasons and 1 wet season (June 2001 to May 2002). The remaining 34 were excluded because of their absence from the village for more than 4 consecutive visits or they delivered before the rainy

المجلة الصحية لشرق المتوسط، منظمة الصحة العالمية، المجلد التاسع، العدد ؟، ب..r 
Table 1 Comparison of variables between pregnant and control (non-pregnant) women

\begin{tabular}{|c|c|c|c|c|c|}
\hline \multirow[t]{2}{*}{ Variable } & \multicolumn{2}{|c|}{$\begin{array}{l}\text { Pregnant women } \\
\qquad(n=86)\end{array}$} & \multicolumn{2}{|c|}{$\begin{array}{c}\text { Control women } \\
(n=89)\end{array}$} & $P$-value \\
\hline & \multicolumn{2}{|c|}{ Mean $\pm s$} & \multicolumn{2}{|c|}{ Mean $\pm s$} & \\
\hline Age (years) & \multicolumn{2}{|c|}{$25.4 \pm 5.9$} & \multicolumn{2}{|c|}{$24.4 \pm 4.9$} & 0.224 \\
\hline Parity (No.) & \multicolumn{2}{|c|}{$2.1 \pm 2.2$} & \multicolumn{2}{|c|}{$2.4 \pm 2.5$} & 0.401 \\
\hline Weight (kg) & \multicolumn{2}{|c|}{$58.5 \pm 9.7$} & \multicolumn{2}{|c|}{$56.5 \pm 8.7$} & 0.086 \\
\hline \multirow[t]{2}{*}{ Visits to the clinic (No.) } & \multicolumn{2}{|c|}{$8.1 \pm 3.4$} & \multicolumn{2}{|c|}{$8.9 \pm 3.8$} & 0.145 \\
\hline & No. & $\%$ & No. & $\%$ & \\
\hline History of abortion & 27 & 31.0 & 21 & 34.7 & 0.248 \\
\hline High-risk obstetric history & 7 & 8.1 & 6 & 11.2 & 0.724 \\
\hline Incidence of malaria & 15 & 17.4 & 5 & 5.6 & 0.014 \\
\hline
\end{tabular}

$\mathrm{s}=$ standard deviation

$\mathrm{n}=$ number of participants.

season. As shown in Table 1, no significant differences were seen between the 2 groups of women (pregnant and non-pregnant controls) in basic characteristics. None of the women in the control group became pregnant during the 1-year study period. The mean gestational age $\pm \mathrm{SD}$ of pregnant women at the time of enrolment was $22.2 \pm 9.1$ weeks.

\section{Malaria during pregnancy}

All infections occurred during the transmission season following the rainy season. All infections were due to $P$. falciparum and no $P$. vivax or $P$. malariae was detected. Fifteen out of $86(15 / 86)$ pregnant women became infected with $P$. falciparum versus 5 out of $89(5 / 89)$ in the control group. As shown in Table 1, there was a significant difference in the incidence of infection between the 2 groups $(17.4 \%$ versus $5.6 \%, P=0.014$ ).
Malaria infections were detected in $22.2 \%(6 / 27)$ of gravida 1 women, $8.3 \%$ (1/12) of gravida 2 and $17.0 \%(8 / 47)$ of gravida $3+$. There was no statistical difference in the incidence of malaria infection between primigravidae and multigravidae (22.2\% versus $15.3 \%, P=0.4$ ).

Eleven $(73.3 \%)$ of the 15 cases of infection occurred in the third trimester of pregnancy, while only 4/15 (26.7\%) were in the second trimester and none in the first trimester. The mean gestational age of the fetus for women with infections was 29.9 \pm 0.8 weeks.

Most of the infections (66.6\%) were detected by the presence of the asexual stage of $P$. falciparum in peripheral blood smear and the women were symptomatic (e.g. fever, headache, joint pain) at presentation. 
Malaria and haemoglobin levels

Table 2 compares different variables among the infected $(n=15)$ and non-infected $(n=71)$ pregnant women. There was no significant difference in the incidence of anaemia between the pregnant women who were infected and those who were not $(2 / 15$ versus $5 / 71, P=0.6)$. Only 1 of the infected pregnant women presented with severe anaemia (haemoglobin level $4.5 \mathrm{~g} / \mathrm{dL}$ ). The mean \pm SD haemoglobin levels at enrolment were not statistically different in pregnant patients who developed malaria infection compared with those who did not: $9.35 \pm 0.80 \mathrm{~g} / \mathrm{dL}$ versus $9.32 \pm$ $1.10 \mathrm{~g} / \mathrm{dL}(P=0.8)$. However, at term, the mean haemoglobin levels were significantly lower among those who developed malaria during pregnancy: $9.10 \pm 1.30 \mathrm{~g} / \mathrm{dL}$ versus $9.50 \pm 0.60 \mathrm{~g} / \mathrm{dL}(P=0.069)$ (Table 2$)$.

\section{Malaria and birth weight}

The mean \pm SD birth weight of babies born to malaria-infected women $(n=13$, 2 cases not determined) was significantly lower compared with those born to non-infected women: $2.72 \pm 0.26 \mathrm{~kg}$ versus $2.95 \pm 0.05$ $\mathrm{kg}(P=0.04)$ (Table 2). The mean birth weight of babies born to primigravidae was not statistically different from those born to multiparae, $2.73 \pm 0.56 \mathrm{~kg}$ versus $2.97 \pm$ $0.53 \mathrm{~kg}(P=0.7)$.

\section{Pregnancy outcome}

One maternal death was reported as a complication of septicaemia following obstructed labour. Four perinatal deaths occurred, all in the non-infected group, and no clear reason was identified. One of the non-infected women aborted her fetus at 10 weeks gestational age. Four of the pregnant women (4/86) delivered prematurely (2/15 in the infected group and 2/71 in the noninfected group).

\section{Treatment response}

$P$. falciparum-infected patients (pregnant and controls) received prompt, adequate treatment according to the Sudanese national drug policy and response to treatment was assessed. All the infected women responded satisfactory to quinine therapy; all were symptom-free by day 3 and their blood films were negative on days 7, 14, 21 and 28.

\begin{tabular}{|c|c|c|c|}
\hline \multirow[t]{2}{*}{ Variable } & \multicolumn{2}{|c|}{ Mean $\pm s$} & \multirow[t]{2}{*}{$P$-value } \\
\hline & $\begin{array}{l}\text { Infected } \\
\text { women } \\
(n=15)\end{array}$ & $\begin{array}{c}\text { Non-infected } \\
\text { women } \\
(n=71)\end{array}$ & \\
\hline Age (years) & $24.5 \pm 6.2$ & $26.7 \pm 6.2$ & 0.215 \\
\hline Birth weight (kg) & $2.72 \pm 0.26$ & $2.95 \pm 0.05$ & $<0.001$ \\
\hline Haemoglobin at enrolment $(\mathrm{g} / \mathrm{dL})$ & $9.35 \pm 0.80$ & $9.32 \pm 1.10$ & 0.80 \\
\hline Haemoglobin at term (g/dL) & $9.10 \pm 1.30$ & $9.50 \pm 0.60$ & 0.069 \\
\hline
\end{tabular}

$\mathrm{s}=$ standard deviation.

$\mathrm{n}=$ number of participants.

المجلة الصحية لشرق المتوسط، منظمة الصحة العالمية، المجلد التاسع، العدد ع، ب... 


\section{Discussion}

This was a prospective study of falciparum malaria during pregnancy in an area of seasonal and unstable malaria transmission in the eastern part of Sudan.

The infection rate was significantly higher in the pregnant compared with the non-pregnant women. This finding was supported by data from areas where malaria is hyperendemic [5]. From our 5 years of clinical observations in the area, we believe that the incidence of infection in pregnant women during the study year was surprisingly lower than expected compared with the preceding years. This can be explained by two factors. First, the rainfall during the study period was low. Theander et al. showed that the incidence of malaria in eastern Sudan varies considerably from year to year depending on the rainfall [16]. Secondly, for the first time, a vector control strategy was applied in the area and all houses in the province were sprayed with deltamethrin.

In contrast to studies conducted in areas where malaria transmission is stable $[5,20]$, this study showed that the infection rate was not different between primigravidae and multigravidae. Studies from an area with perennial malaria transmission in Africa showed a higher prevalence of infection in all pregnant women but highest in primigravidae [5,20], with both gravidity and premunition (i.e. partial immunity in which parasitaemia is better tolerated) influencing susceptibility to malaria infection [21-23]. In addition, there was no significant difference in age between infected and non-infected pregnant women. Giha et al. observed that in eastern Sudan the incidence of malaria was significantly higher in individuals aged 5 to 19 years compared with older age groups ( $>20$ years); however, pregnant women were not included in that study [24]. Bouyou-Akotet et al. showed that primigravidae and young pregnant women are most susceptible to malaria infection [25].

In this study, there was strong tendency for a lower mean haemoglobin concentration near delivery in those pregnant women who developed malaria. Data from an area of unstable malaria transmission in Thailand [15] showed significantly lower haemoglobin concentrations in pregnant women who became infected despite prompt diagnosis and antimalarial treatment, and the study was further confirmed by another study from areas of unstable malaria transmission in Ethiopia [26].

The mean birth weight of babies in our study was significantly lower in the mothers who became infected during pregnancy. The finding is consistent with the observation by Nosten et al., where the birth weight was significantly lower in the pregnant women who developed malaria despite early diagnosis and treatment [15]. Studies from areas of stable malaria transmission $[7,15,27]$, including areas of Ethiopia [26], also found a significant association between malaria and reduced birth weights. However, in areas of unstable malaria in Ethiopia [26], Newman found no significant association between malaria and decreased birth weight and this contrasts with our own observation and Nosten's [15]. Malaria was a known cause of low birth weight in the central Sudan, as well as in the other African countries $[28,29]$.

In our study the reduction in the birth weight of babies born to pregnant women who became infected occurred in spite of active diagnosis and effective therapy with the standard quinine regime. In our study area, we have recently shown that $9.3 \%$ of $P$. falciparum-infected patients treated with quinine developed late recrudescence

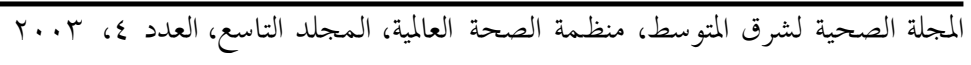


of parasitaemia and malaria symptoms [30]. Sulphadoxine/pyrimethamine was used as an alternative therapy and no resistance was reported to this drug. Low birth weight has been closely linked with 'placental' rather than 'peripheral' parasitaemia [31]. The parasite sequestration in the placenta is considered to be the main pathological mechanism [32] and the placenta is often heavily infected with $P$. falciparum [33]. Placental infection leads to thickening of the syncytiotrophoblasts, abnormal utero/placental blood flow and placental insufficiency. As low birth weight is the leading cause of infant mortality [34], prevention of this should be a major goal.

In areas of moderate or high malaria transmission, including large parts of Africa, malaria in pregnancy is a common cause of severe maternal anaemia and reduced birth weight of babies, these complications being more common in primigravidae than multigravidae [35]. In our study, there was no significant difference between the birth weight of babies born to primigravidae or multigravidae.

Pregnancy is known to induce a state of immune suppression. Timing of peak suppression and increased susceptibility to infection is of importance for timing of possible intervention to reduce severe adverse effects of malaria on both the mother and the baby. In our study, over $70 \%$ of the infections were in the third trimester and no infections were reported during the first trimester. This may be because pregnant women presented to the antenatal care clinic for the first time during the second trimester, as the mean gestational at enrolment was 22 weeks. A peak incidence rate of malaria attacks during the second trimester was observed in areas with perennial transmission [36]. In this study, all infections occurred during the narrow transmission season following the rainy season. Almost two-thirds of infections were symptomatic which may suggest that the level of immunity is low and inadequate. This is in contrast to data from areas where malaria is stable and hyper-endemic, malaria is still frequently asymptomatic, so may go unsuspected and undetectable, but may be associated with placental parasitization [20]. In spite of the fact that most of the infections were detected actively after development of clinical malaria, no mortality was associated with malaria.

Thus, in these areas, the prevention of low birth weight could be possible by measurements such as reduction of exposure to the vector, and effective preventive treatment with sulphadoxine/pyrimethamine provided in 2 single doses during and at the end of the transmission season to all pregnant women (during the second and third trimester) irrespective of parity. In addition, routine hospital data such as birth weight and number of malaria cases can provide information on the level of malaria transmission useful for the health services to target appropriate malaria interventions and allocate resources to control outbreaks of malaria epidemics.

\section{Acknowledgements}

We wish to thank all pregnant women and their families who participated in the study and we are very grateful to the local health authorities in Kassala State. Thanks are also extended to Mr Abdalla Ahmed Hufazalla and Mr Tarig Elfaki for their excellent technical assistance. Both authors, Gehad ElGhazali and Isheg Adam, contributed equally to this work.

This investigation received technical and financial support from the joint WHO Eastern Mediterranean Region (EMRO), Division of Communicable Diseases

المجلة الصحية لشرق المتوسط، منظمة الصحة العالمية، المجلد التاسع، العدد ع، ب...T 
(DCD) and the WHO Special Programme for Research and Training in Tropical Diseases (TDR): the EMRO/DCD/TDR Small
Grants Scheme for Operational Research in Tropical and Communicable Diseases

\section{References}

1. Vleugels MP et al. Cortisol and loss of malaria immunity in pregnancy. British journal of obstetrics and gynaecology, 1987, 94:758-64.

2. Fievet $\mathrm{N}$ et al. Immune response to Plasmodium falciparum antigens in Cameroonian primigravidae: evolution after delivery and during second pregnancy. Clinical and experimental immunology, 1997, 107:462-7.

3. Menon R. Pregnancy and malaria. Medical journal of Malaysia, 1972, 27:115-9.

4. Brabin BJ et al. A study of the consequences of malaria infection in pregnant women and their infants. Parasitologia, 1993, 35(suppl.):9-11.

5. McGregor IA. Epidemiology, malaria and pregnancy. American journal of tropical medicine and hygiene, 1984, 33:51725.

6. Brabin BJ et al. Consequences of maternal anaemia on outcome of pregnancy in a malaria endemic area in Papua New Guinea. Annals of tropical medicine and parasitology, 1990, 84:11-24.

7. Brabin B. An assessment of low birthweight risk in primiparae as an indicator of malaria control in pregnancy. International journal of epidemiology, 1991, 20:276-83.

8. McGregor IA, Wilson ME, Billewicz WZ. Malaria infection of the placenta in the Gambia, West Africa; its incidence and relationship to stillbirth, birthweight and placental weight. Transactions of the Royal Society of Tropical Medicine and Hygiene, 1983, 77:232-44.
9. Greenwood BM et al. The effects of malaria chemoprophylaxis given by traditional birth attendants on the course and outcome of pregnancy. Transactions of the Royal Society of Tropical Medicine and Hygiene, 1989, 83:589-94.

10. Greenwood AM et al. The distribution of birth weights in Gambian women who received malaria chemoprophylaxis during their first pregnancy and in control women. Transactions of the Royal Society of Tropical Medicine and Hygiene, 1994, 88:311-2.

11. Menendez C. Malaria during pregnancy: a priority area of malaria research and control. Parasitology today, 1995, 11: 178-83.

12. Garner P, Brabin B. A review of randomised controlled trials of routine antimalarial drug prophylaxis during pregnancy in endemic malarious areas. Bulletin of the World Health Organization, 1994, 72:89-99.

13. Brabin BJ. An analysis of malaria in pregnancy in Africa. Bulletin of the World Health Organization, 1983, 61:1005-16.

14. Snow RW et al. Relation between severe malaria mortality in children and level of Plasmodium falciparum transmission in Africa. Lancet, 1977, 349:1650-4.

15. Nosten $\mathrm{F}$ et al. Malaria during pregnancy in an area of unstable endemicity. Transactions of the Royal Society of Tropical Medicine and Hygiene, 1991, 85:424-9.

16. Theander TG. Unstable malaria in Sudan: the influence of the dry season. Malaria in areas of unstable and sea-

المجلة الصحية لشرق المتوسط، منظمة الصحة العالمية، المجلد التاسع، العدد ع، ب... 
sonal transmission. Lessons from Daraweesh. Transactions of the Royal Society of Tropical Medicine and Hygiene, 1998, 92:589-92.

17. Bayoumi RA et al. Chloroquine-resistant Plasmodium falciparum in eastern Sudan. Acta tropica, 1989, 46:157-65.

18. Barduagni $P$ et al. Performance of Sahli and colour scale methods in diagnosing anaemia among school children in low prevalence areas. Tropical medicine and international health, 2003, 8:615-8.

19. Guidelines for good clinical practice (GCP) for trials on pharmaceutical products. Geneva, World Health Organization, 1995 (WHO Technical Report Series, No. 850).

20. Shulman CE et al. Malaria in pregnancy: adverse effects on haemoglobin levels and birthweight in primigravidae and multigravidae. Tropical medicine and international health, 2001, 6:770-8.

21. Mutabingwa TK et al. Malaria chemosuppression during pregnancy. IV. Its effects on the newborn's passive malaria immunity. Tropical and geographical medicine, 1993, 45:150-6.

22. Cot $\mathrm{M}$ et al. Increase of birth weight following chloroquine chemoprophylaxis during the first pregnancy: results of a randomized trial in Cameroon. American journal of tropical medicine and hygiene, 1995, 53:581-5.

23. Bouvier $P$ et al. Seasonality, malaria, and impact of prophylaxis in a West African village. II. Effect on birthweight. American journal of tropical medicine and hygiene, 1997, 56:384-9.

24. Giha HA et al. The epidemiology of febrile malaria episodes in an area of unstable and seasonal transmission. Transactions of the Royal Society of Tropical Medicine and Hygiene, 2000, 94:645-51.
25. Bouyou-Akotet MK et al. Prevalence of Plasmodium falciparum malaria infection in pregnant women in Gabon. Malaria journal, 2003, 2:18-24.

26. Newman RD et al. Burden of malaria during pregnancy in areas of stable and unstable transmission in Ethiopia during a nonepidemic year. Journal of infectious diseases, 2003, 187:1765-72.

27. Mutabingwa TK et al. Malaria chemosuppression during pregnancy. VI. Some epidemiological aspects of malaria in infants. Tropical and geographical medicine, 1994, 46:1-7.

28. Taha T, Gray RH, Mohamedani AA. Malaria and low birth weight in central Sudan. American journal of epidemiology, 1993, 138:318-25.

29. Guyatt HI, Snow RW. Malaria in pregnancy as indirect cause of infant mortality in sub-Saharan Africa. Transactions of the Royal Society of Tropical Medicine and Hygiene, 2001, 95:569-76.

30. Elghazali $G$ et al. Chloroquine resistance and drug response to quinine in Plasmodium falciparum from new Halfa, Eastern Sudan. Annals of tropical medicine and parasitology, 2004 (in press).

31. Galbraith RM et al. The human maternofoetal relationship in malaria: I. Identification of pigment and parasites in the placenta. Transactions of the Royal Society of Tropical Medicine and Hygiene, 1989, 74:52-60.

32. Shulman CE, Dorman EK. Importance and prevention of malaria in pregnancy. Transactions of the Royal Society of Tropical Medicine and Hygiene, 2003, 97:30-5.

33. Diagne $\mathrm{N}$ et al. Incidence of clinical malaria in pregnant women exposed to intense perennial transmission. Transactions of the Royal Society of Tropical

المجلة الصحية لشرق المتوسط، منظمة الصحة العالمية، المجلد التاسع، العدد ع، ب... 
Medicine and Hygiene, 1997, 91:16670 .

34. Menendez $\mathrm{C}$ et al. The impact of placental malaria on gestational age and birth weight. Journal of infectious diseases, 2000, 181:1740-5.

35. Fried M, Duffy PE. Adherence of Plasmoduim falciparum to chondrotin sulphate A in human placenta. Science, 1996, 272:1502-4.

36. Luxemburger $\mathrm{C}$ et al. Effects of malaria during pregnancy on infant mortality in an area of low malaria transmission. American journal of epidemiology, 2001, 154:459-65.

\section{Correction}

Prevalence of smoking and age of initiation in Alexandria, Egypt. R.M. Youssef, S.A. AbouKhatwa and H.M. Fouad. Eastern Mediterranean Health Journal, 2002, Vol. 8 Nos 4/5, pages 626-637.

In Table 3 (page 632), the 95\% CI for the age group 25-34 years should read: 17.74 to 18.99

المجلة الصحية لشرق المتوسط، منظمة الصحة العالمية، المجلد التاسع، العدد ع، ب... 